\title{
Synthesis and crystal structure characterization of thorium trimesate coordination polymers
}

Nicolas P. Martin, Christophe Volkringer*, Clément Falaise, Natacha Henry and Thierry Loiseau

Contribution from Unité de Catalyse et Chimie du Solide (UCCS) - UMR CNRS 8181, Université de Lille, ENSCL, Bat C7, BP 90108, 59652 Villeneuve d'Ascq, France.

* To whom correspondence should be addressed. E-mail: christophe.volkringer@ensc-lille.fr. Phone: (33) 320434 973, Fax: (33) 320434895

\section{Supporting information}

To be submitted to. Cryst. Growth and Design.

Version January 11th, 2016 


\section{Figures}

\section{SEM pictures:}

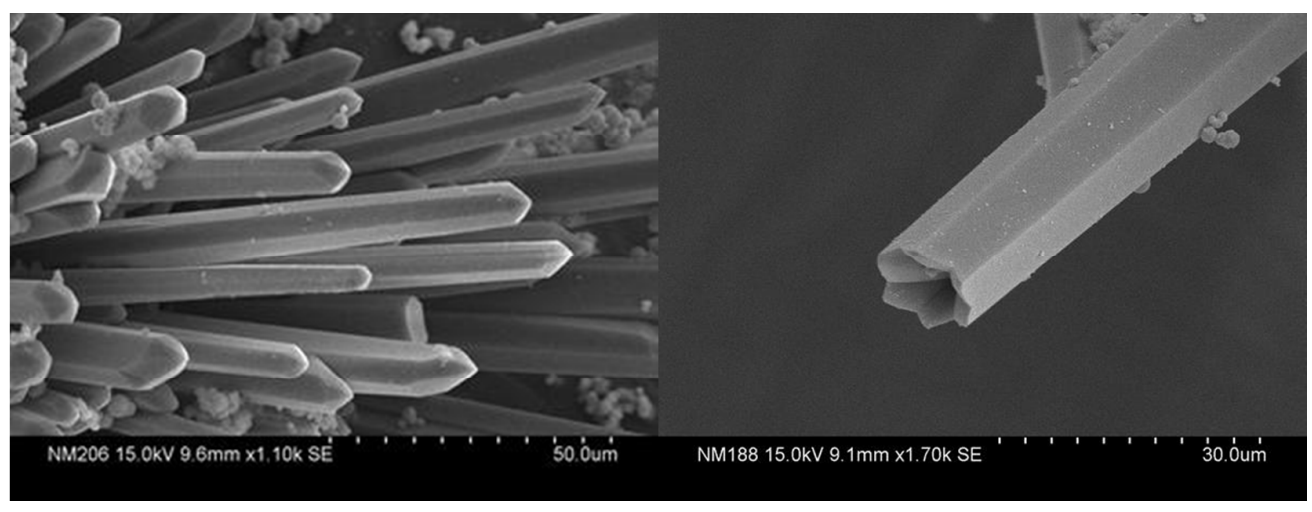

Figure S1a: SEM photographs of (1).

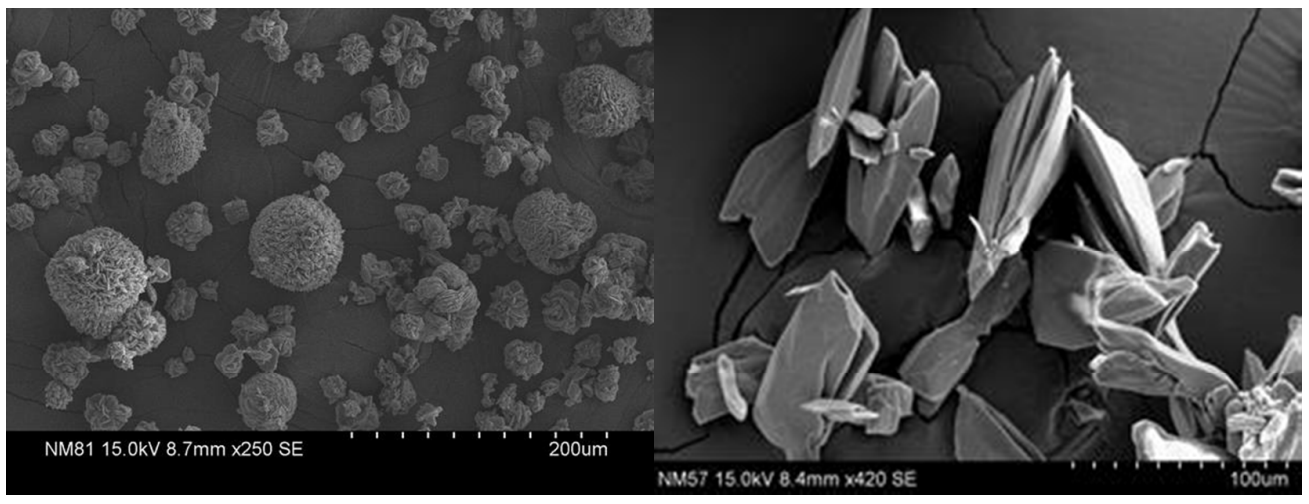

Figure S1b: SEM photographs of (2).

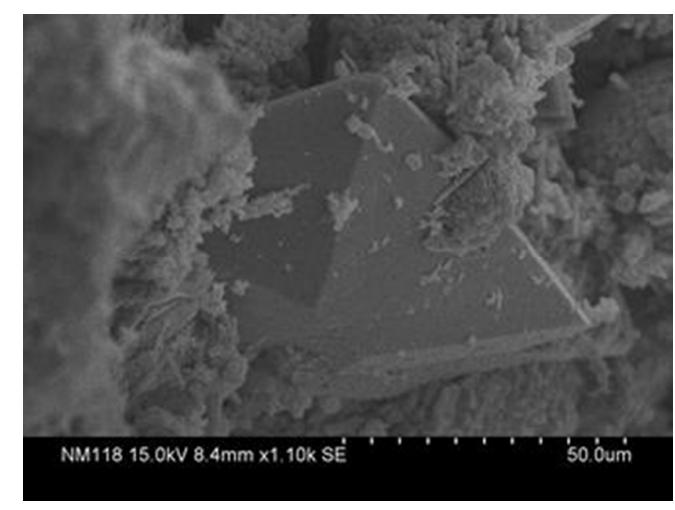

Figure S1c: SEM photograph of (3). 


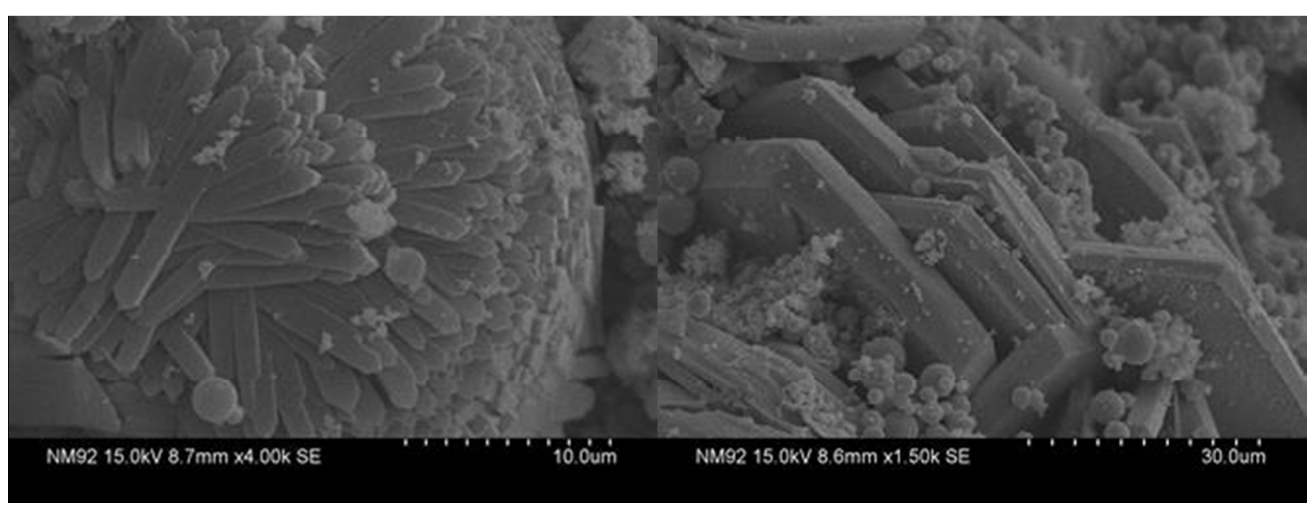

Figure S1d: SEM photographs of (4).

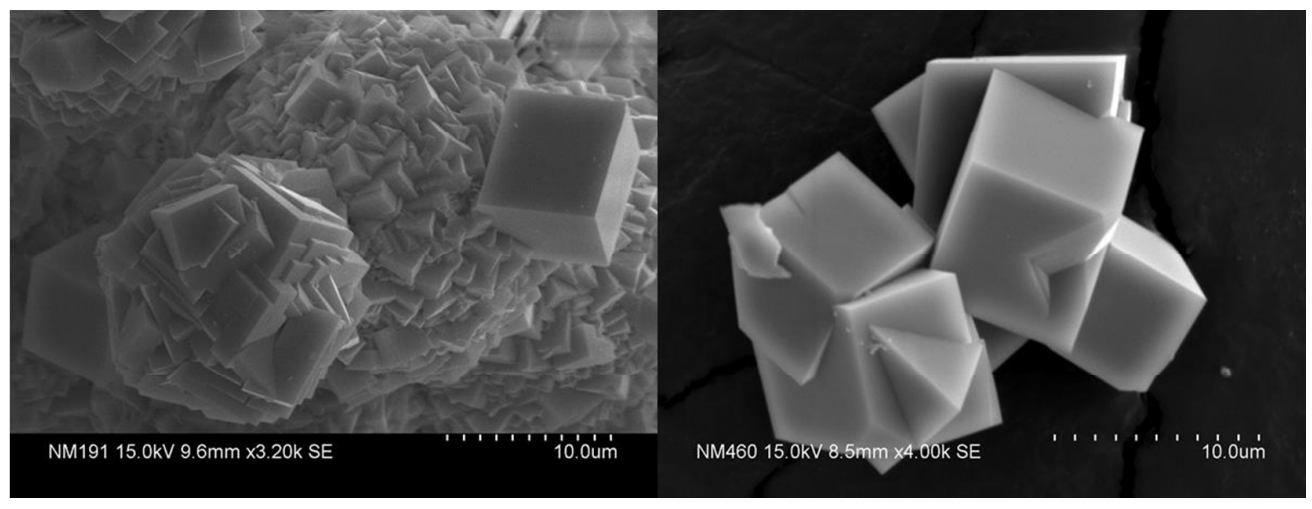

Figure S1e: SEM photographs of (5).

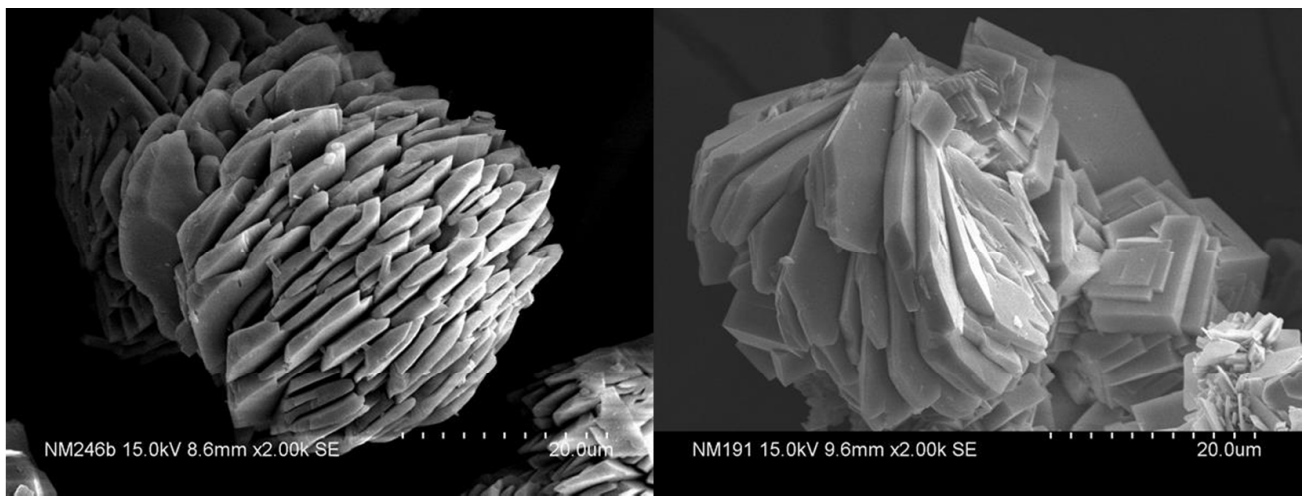

Figure S1f: SEM photographs of (6). 

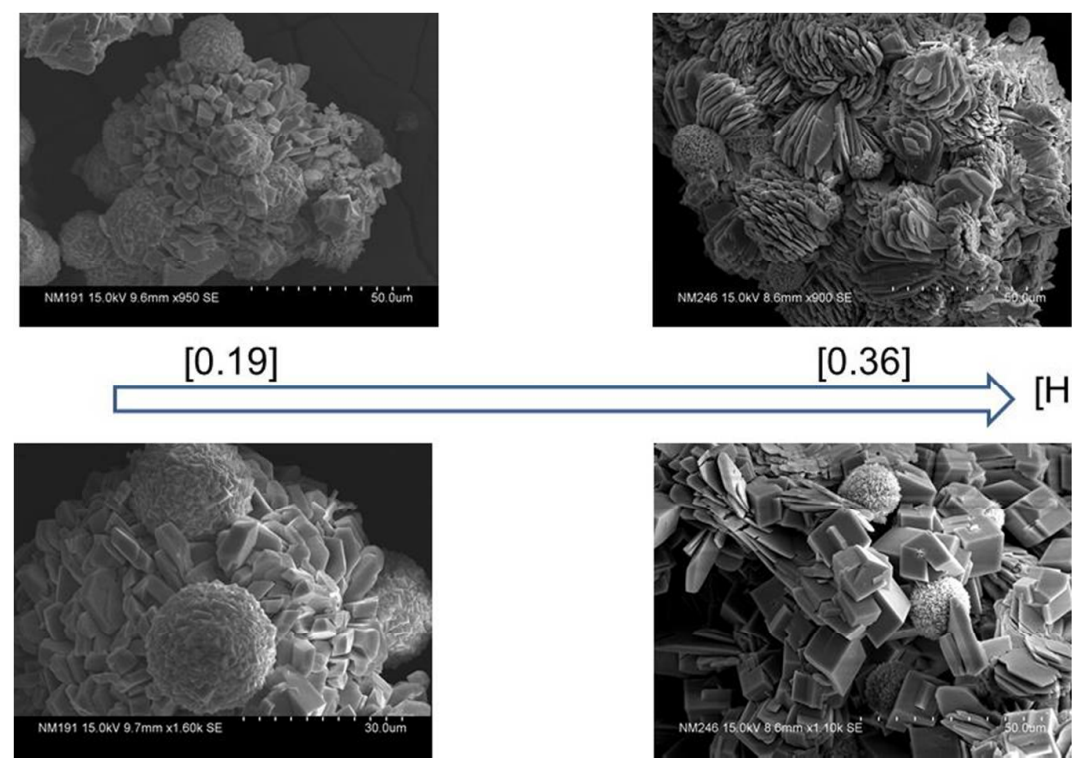

[0.36] $[\mathrm{HF}]$

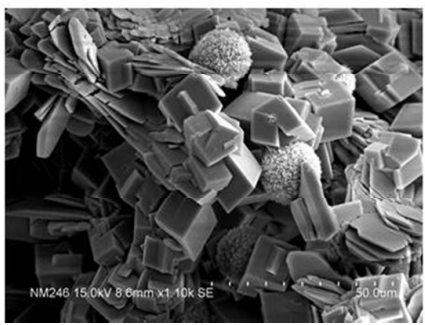

Figure S1g: Influence of HF concentration during the co-crystallization of 5 (cube) and $\mathbf{6}$ (platelet). 

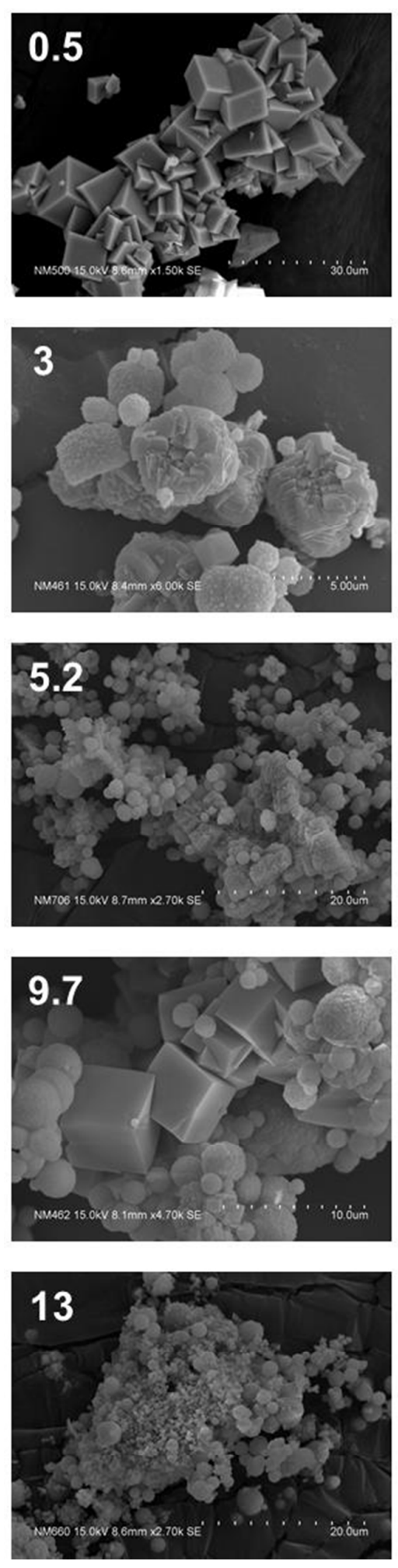
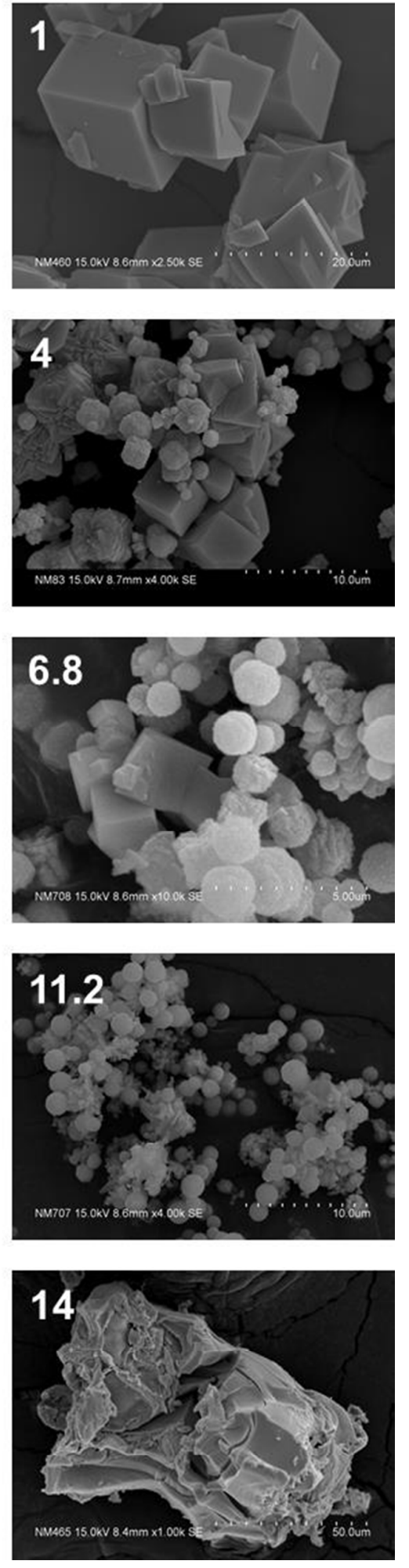

Figure S1h: SEM pictures of solids synthesized in the $\mathrm{pH}$ range $0.5-14$. The value of the $\mathrm{pH}$ is indicated on the top left corner of the picture. At $\mathrm{pH}=0.5,1,3,4$ phase 5 (cube); At $\mathrm{pH}=$ 5.2, 6.8, 9.7 mixture of phase 5 (cube) and phase 6 (sphere); At $\mathrm{pH}=11.2$, phase 5 (cube) + phase 6 and phase 1 which crystallized both as spheres; At pH 13, phase 5 (cube) + phase 6 (sphere) and phase 1 (sphere): At $\mathrm{pH} \mathrm{14,} \mathrm{ThO}_{2}$ (block). 
Powder X-ray diffraction (PXRD):

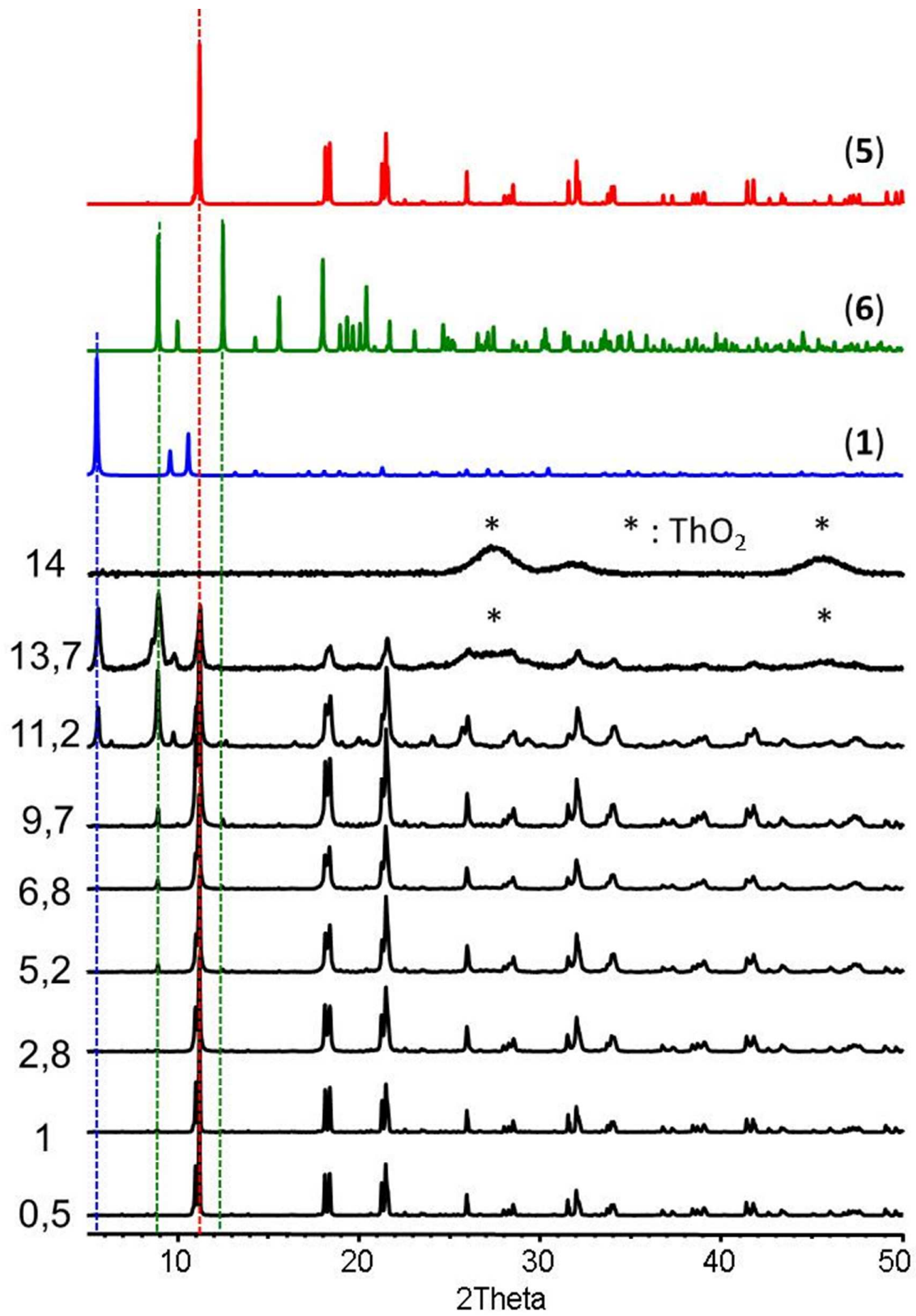

Figure S2a: Experimental powder X-ray patterns of solids synthesized in the $\mathrm{pH}$ range 0.5 14 , compared to the calculated powder X-ray patterns of $\mathbf{1}, \mathbf{5}$ and $\mathbf{6}$ (copper radiation). 


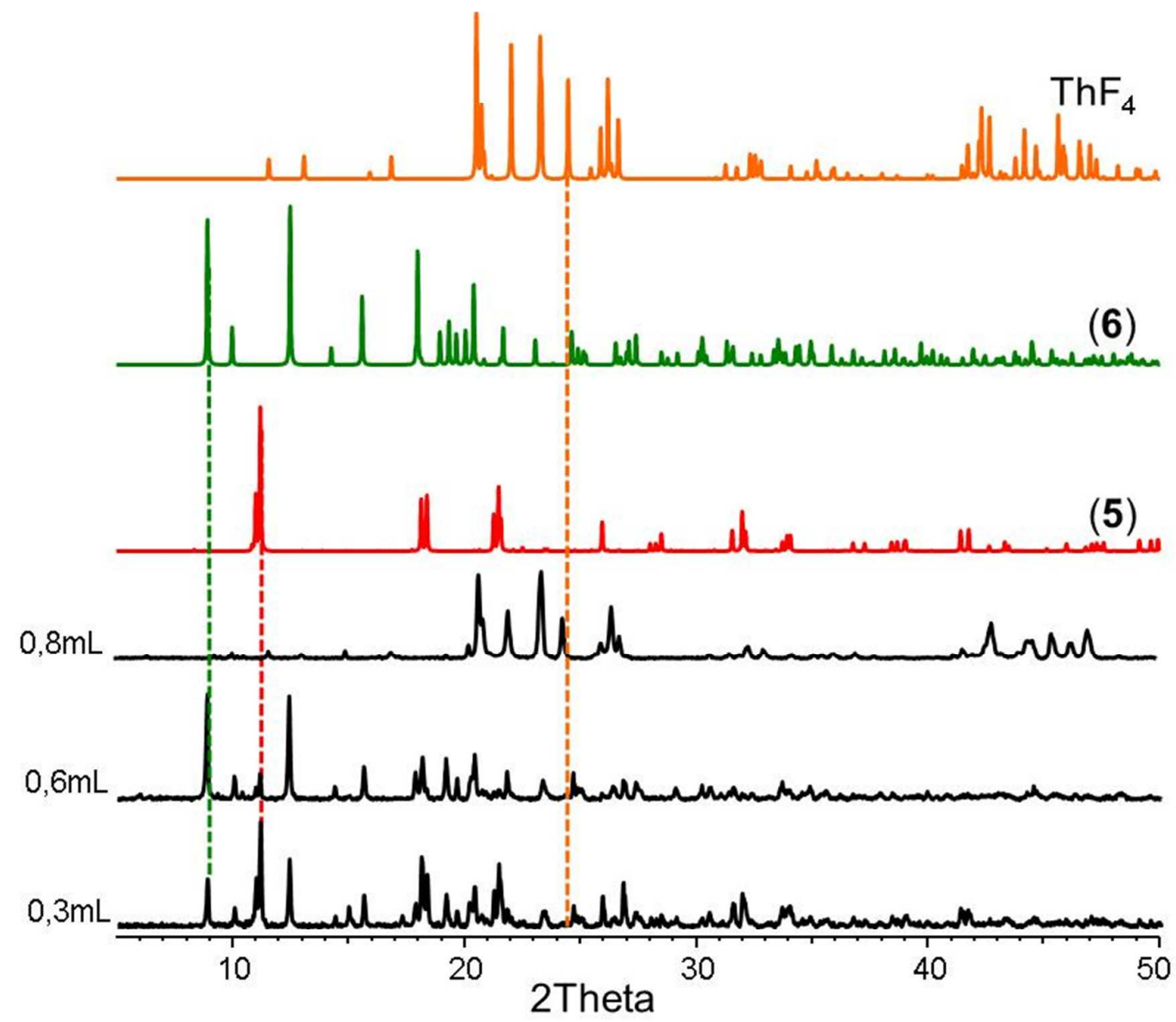

Figure S2b: Experimental powder X-ray patterns of solids synthesized with different amount of hydrofluoric acid, compared with the calculated powder x-ray patterns of $\mathbf{5}, \mathbf{6}$ and $\mathrm{ThF}_{4}$ (copper radiation). 


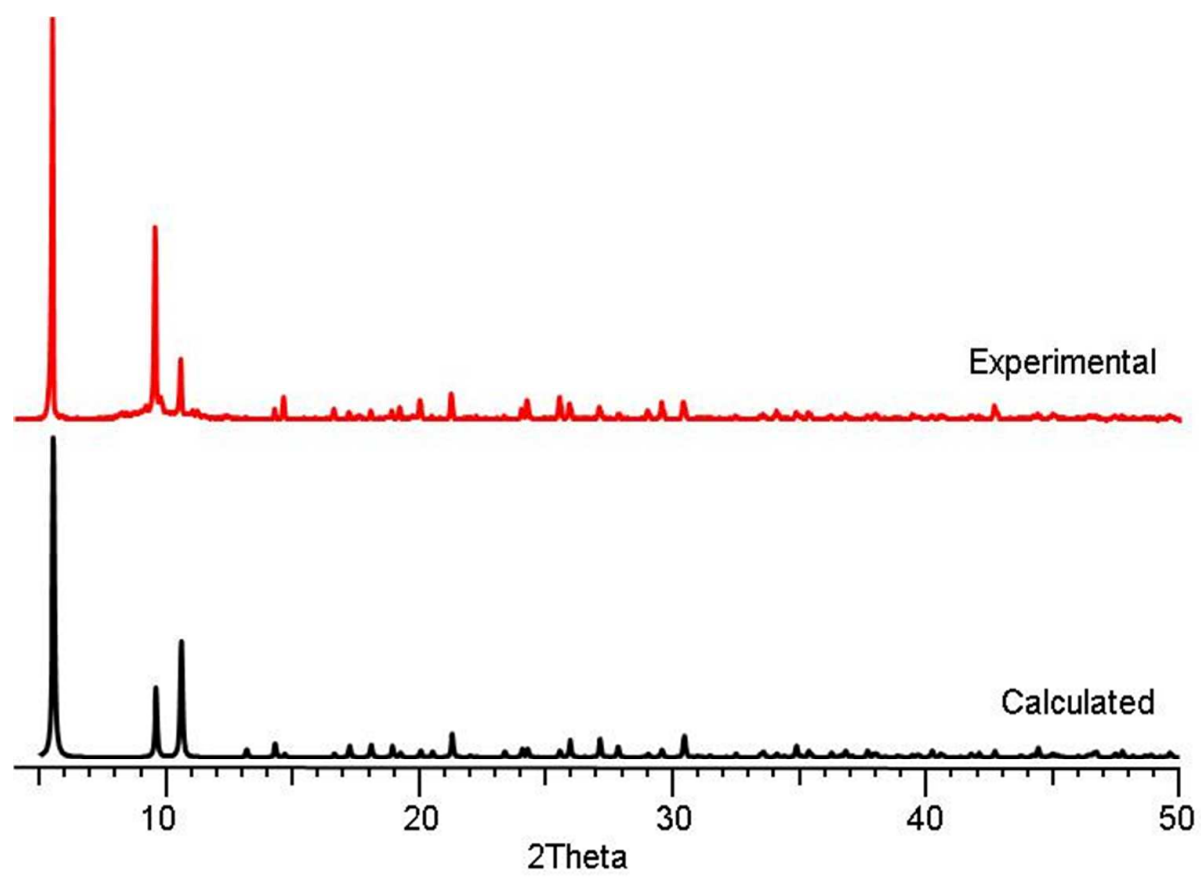

Figure S2c: Experimental and simulated powder XRD diagrams of $\mathbf{1 .}$

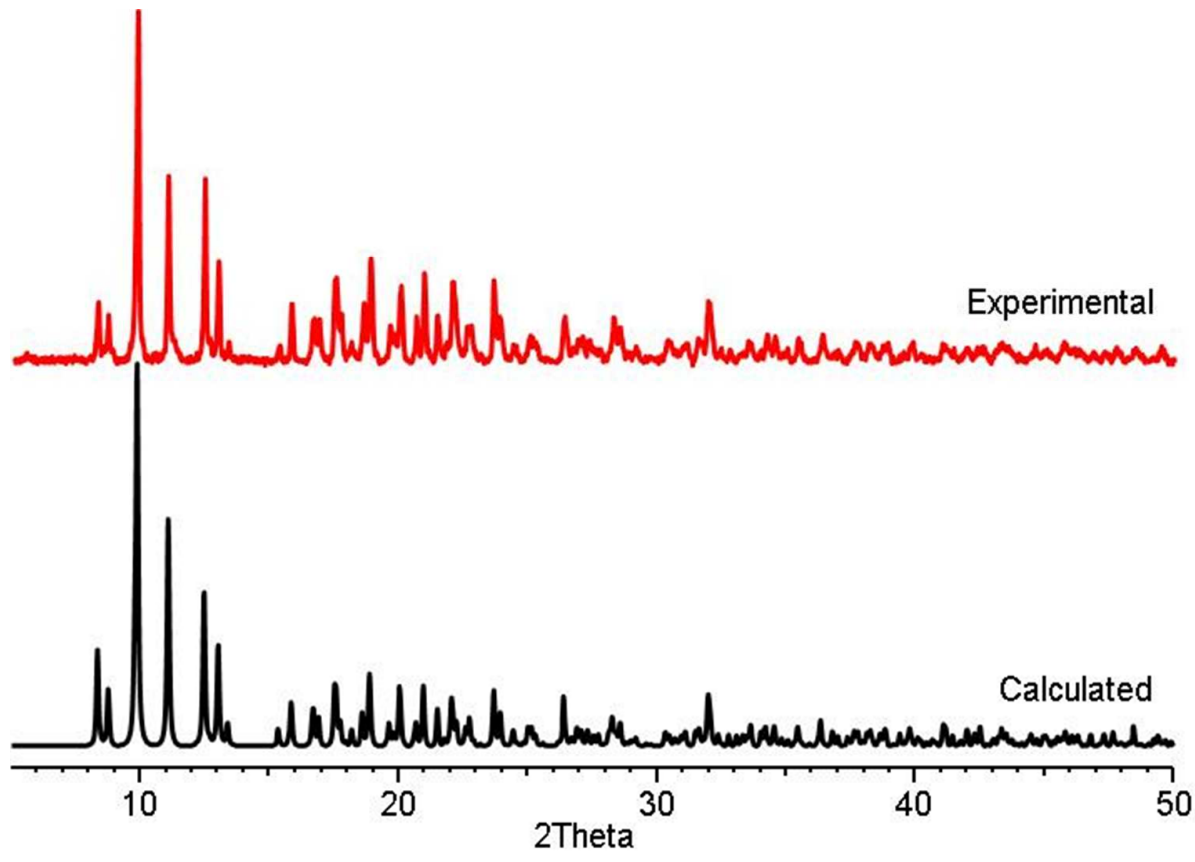

Figure S2d: Experimental and simulated powder XRD diagrams of 2. 


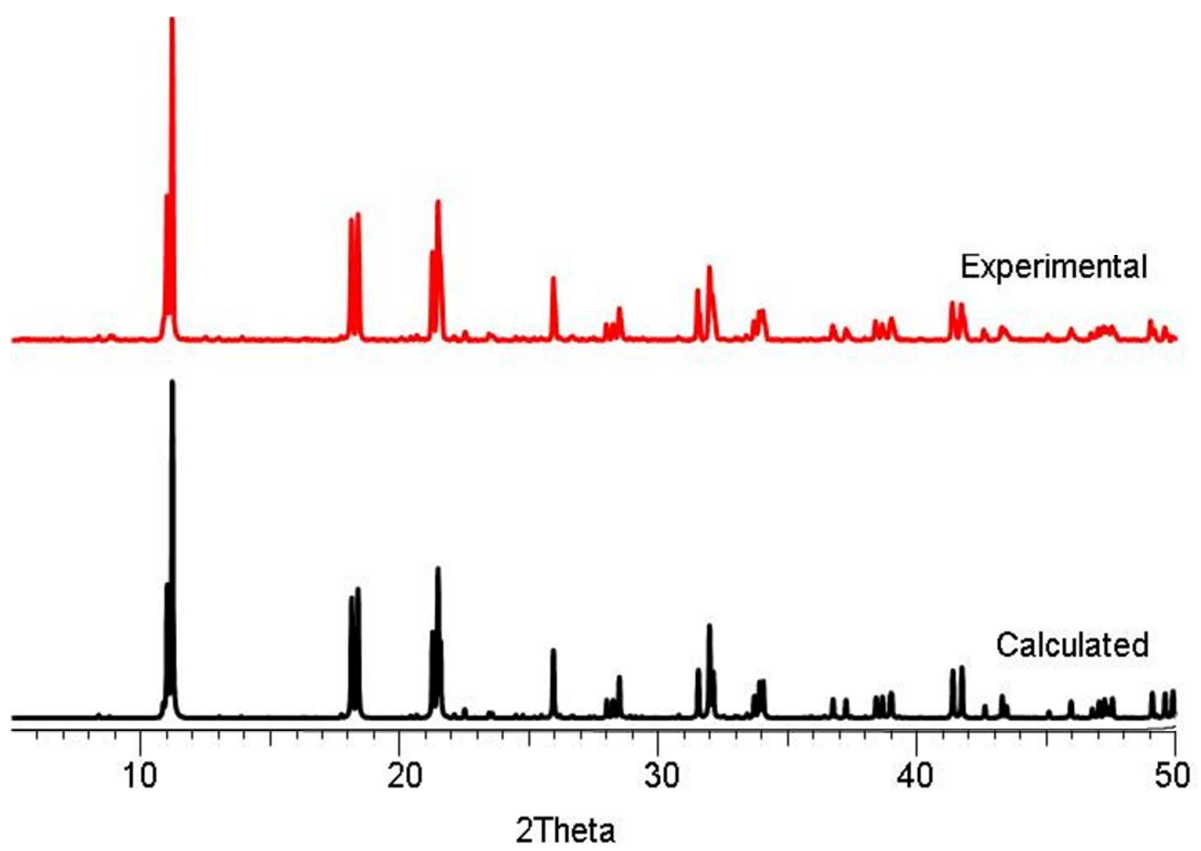

Figure S2e: Experimental and simulated powder XRD diagrams of $\mathbf{5}$. 


\section{Infrared:}

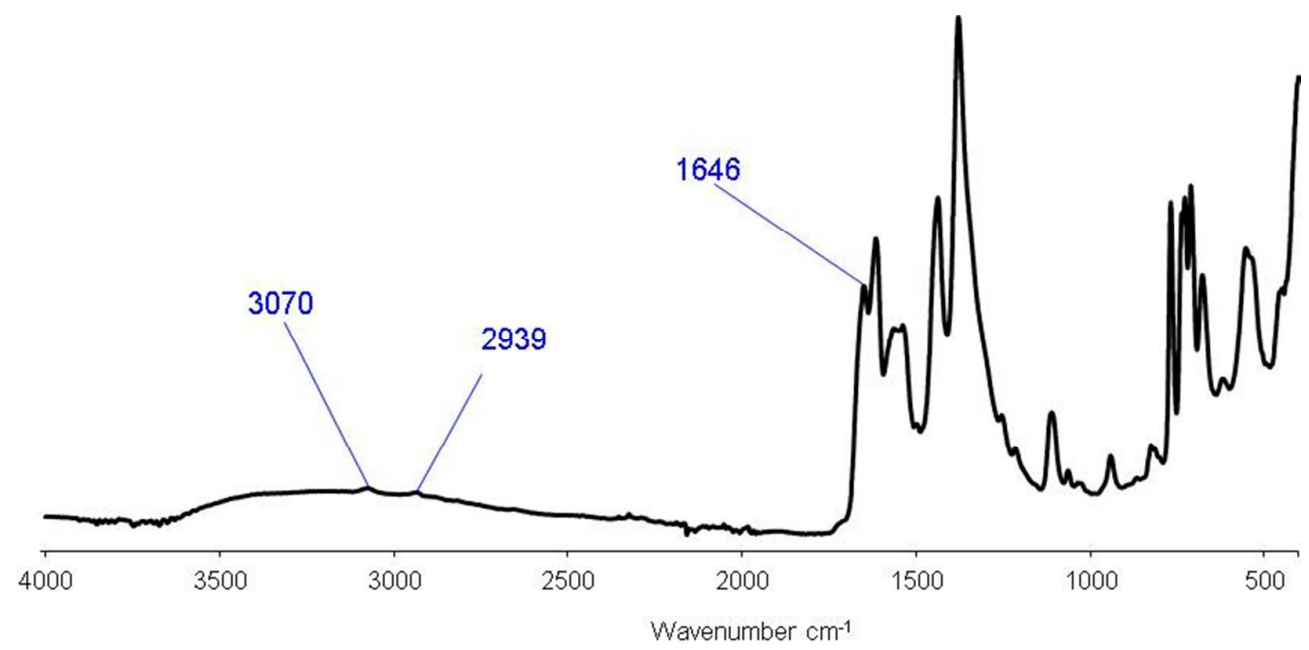

Figure S3a: FT-IR spectrum of 1 collected at room temperature without thermal treatment.

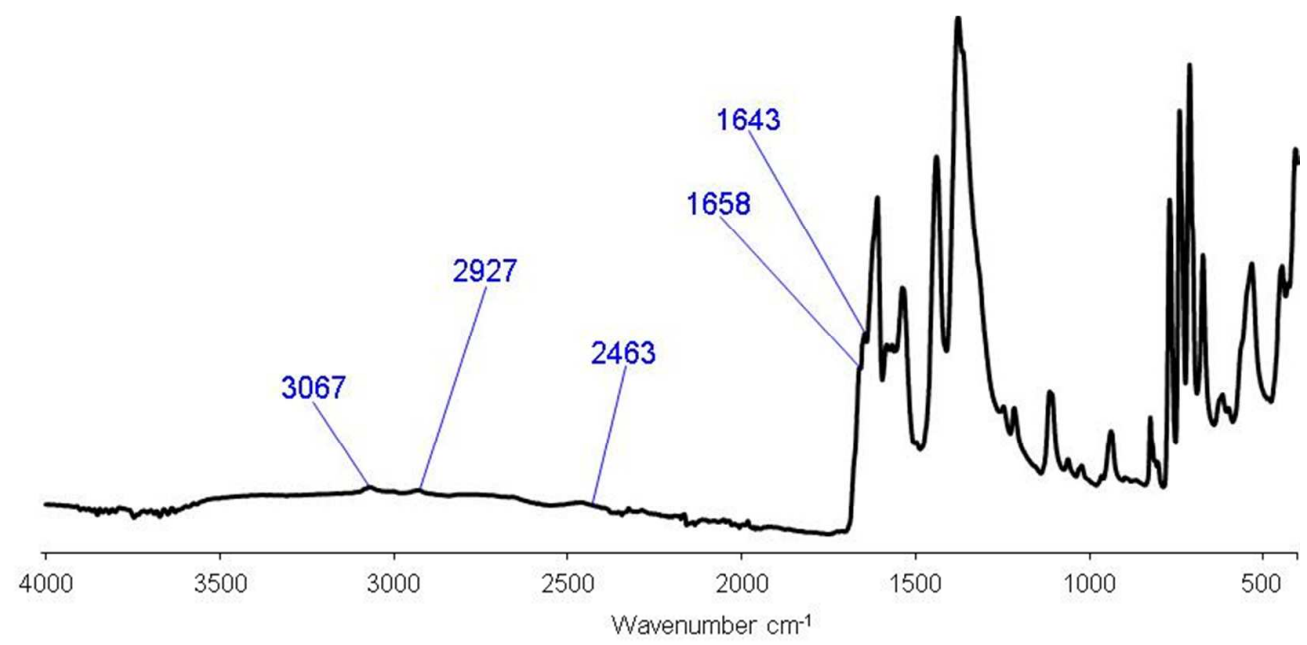

Figure $\mathbf{S} 3 \boldsymbol{b}$ : FT-IR spectrum of $\mathbf{2}$ collected at room temperature. 


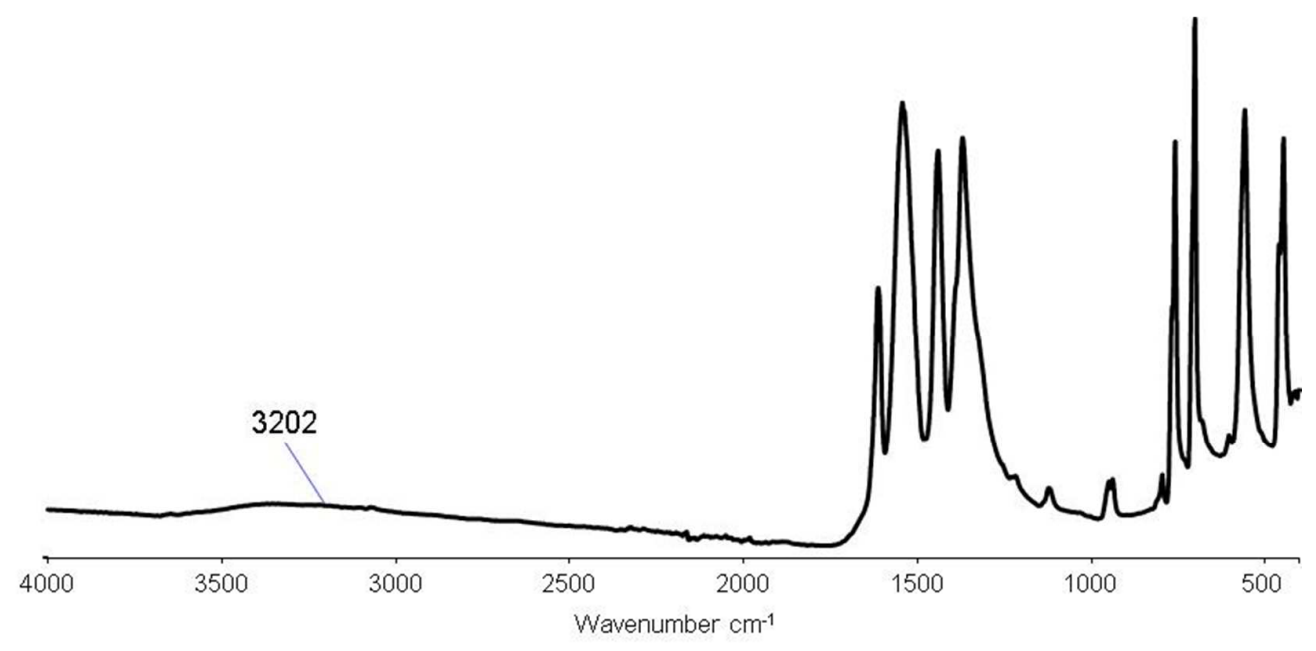

Figure $S 3 c$ : FT-IR spectrum of 5 collected at room temperature. 


\section{Thermal behavior:}

\section{Phase 1:}
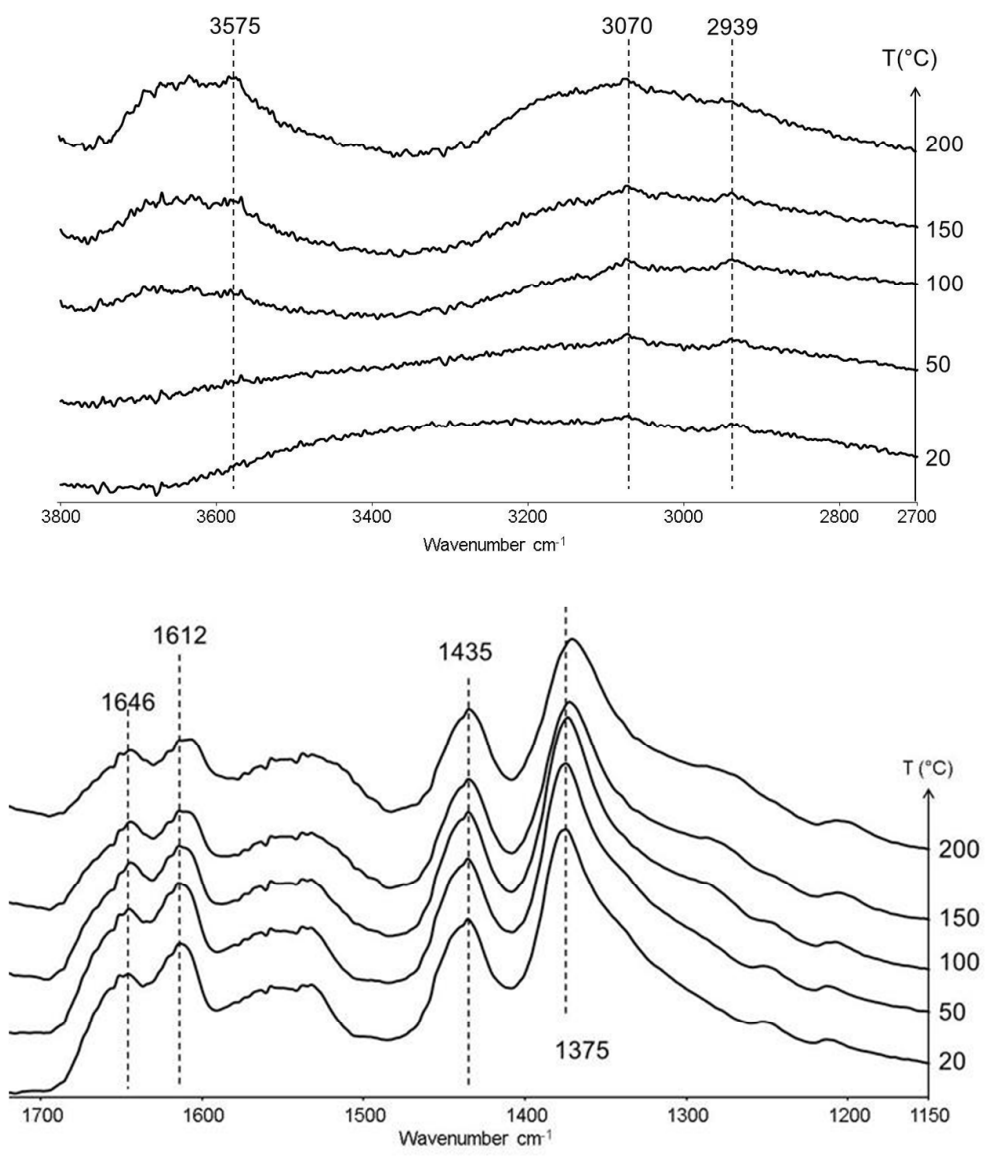

Figure S4a: Evolution of the in situ infrared spectra of 1 as a function of temperature between RT and $200^{\circ} \mathrm{C}$ in the ranges $3800-2700 \mathrm{~cm}^{-1}$ and $1720-1150 \mathrm{~cm}^{-1}$. 


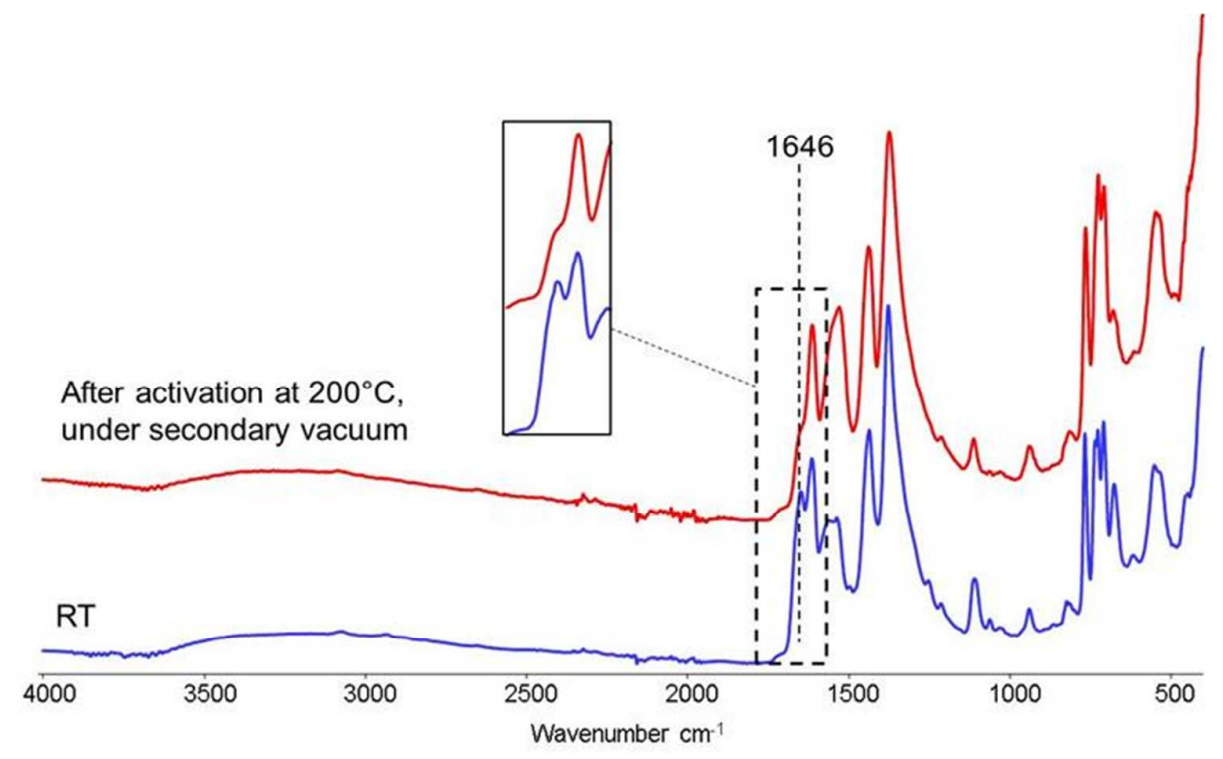

Figure S4b: Comparison between infrared spectra of 1 collected at RT (blue) and after activation at $200^{\circ} \mathrm{C}$ under vacuum (red). It shows that the vibrations at $1646 \mathrm{~cm}^{-1}$ decrease after activation, indicating the partial removal of DMF trapped within the pores of $\mathbf{1}$.

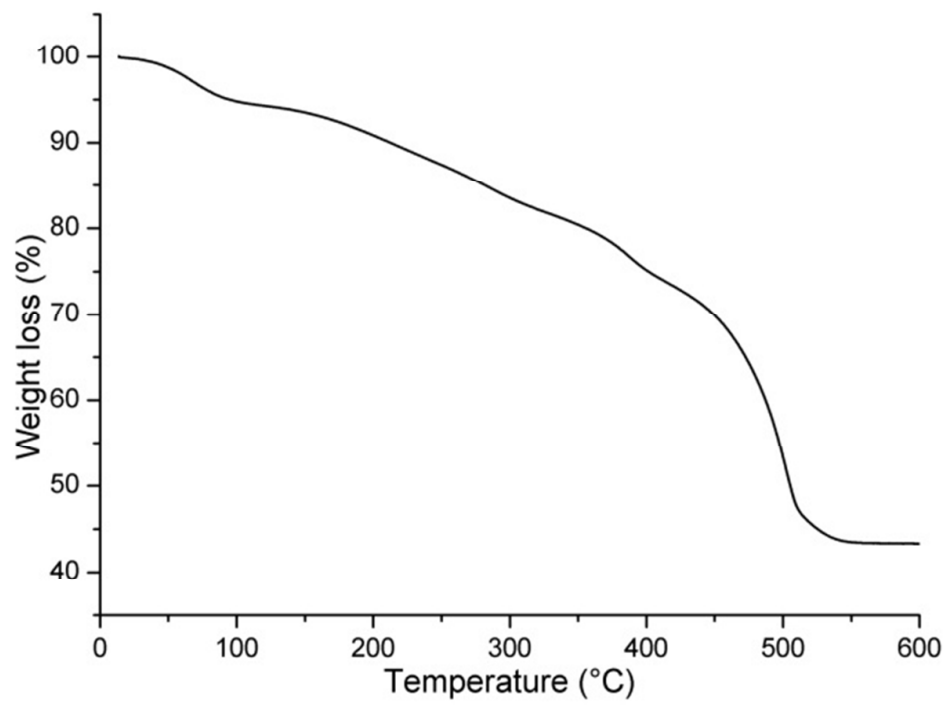

Figure S4c: Thermogravimetric curve of 1 under air atmosphere $\left(5^{\circ} \mathrm{C} \cdot \mathrm{min}^{-1}\right)$. 


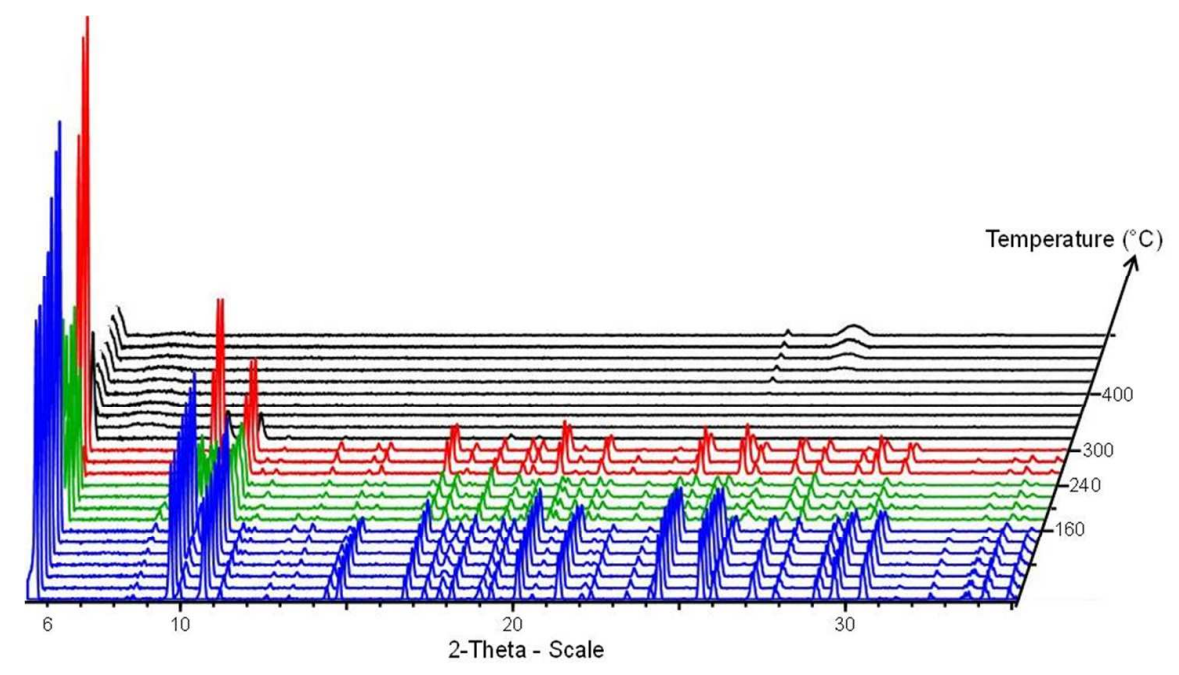

Figure S4d: X-ray thermodiffractogramm of 1 (copper radiation) under air atmosphere. 


\section{Phase 2}
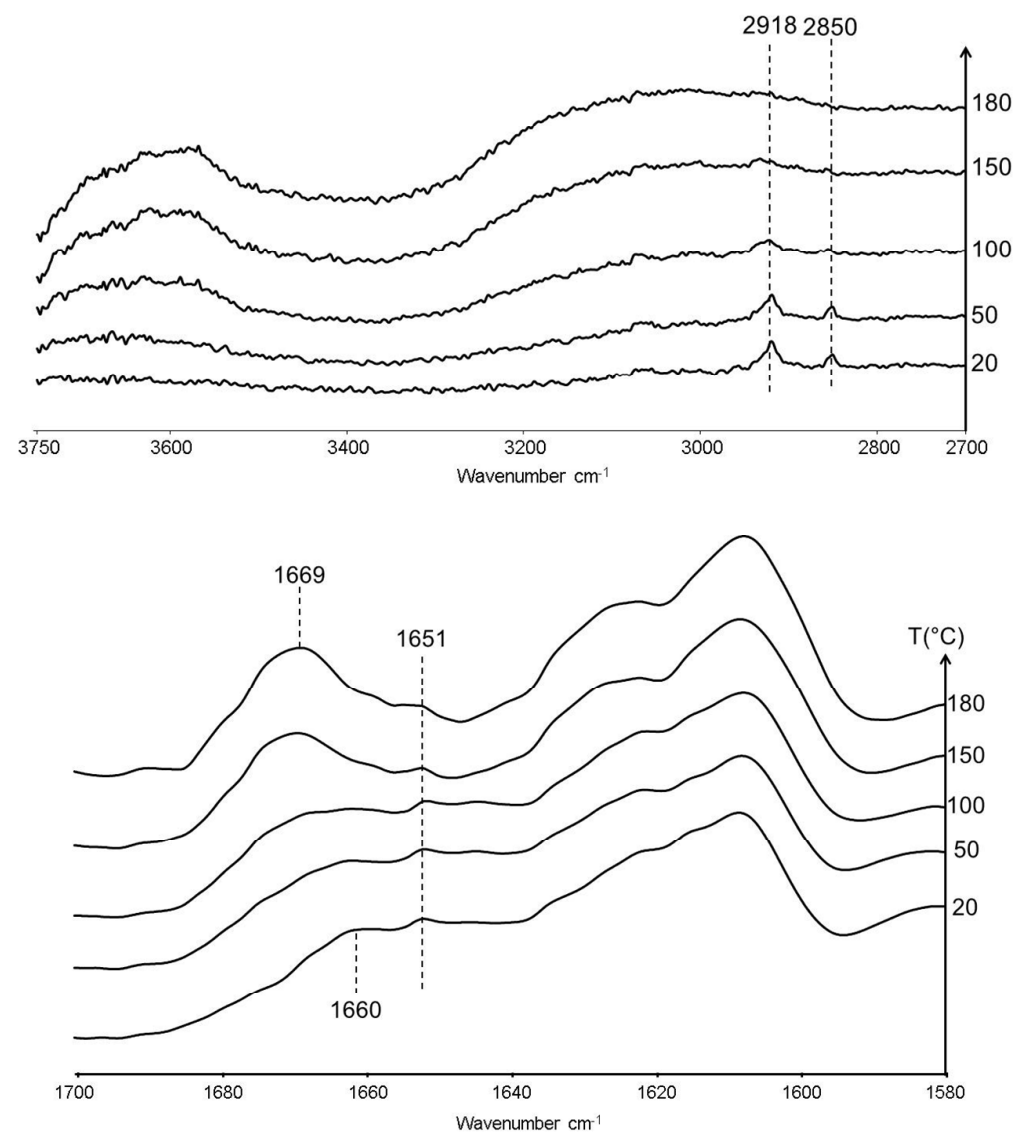

Figure S4e: Evolution of the in situ infrared spectra of $\mathbf{2}$ as a function of temperature between $\mathrm{RT}$ and $200^{\circ} \mathrm{C}$ in the ranges $3750-2700 \mathrm{~cm}^{-1}$ and $1700-1580 \mathrm{~cm}^{-1}$. 


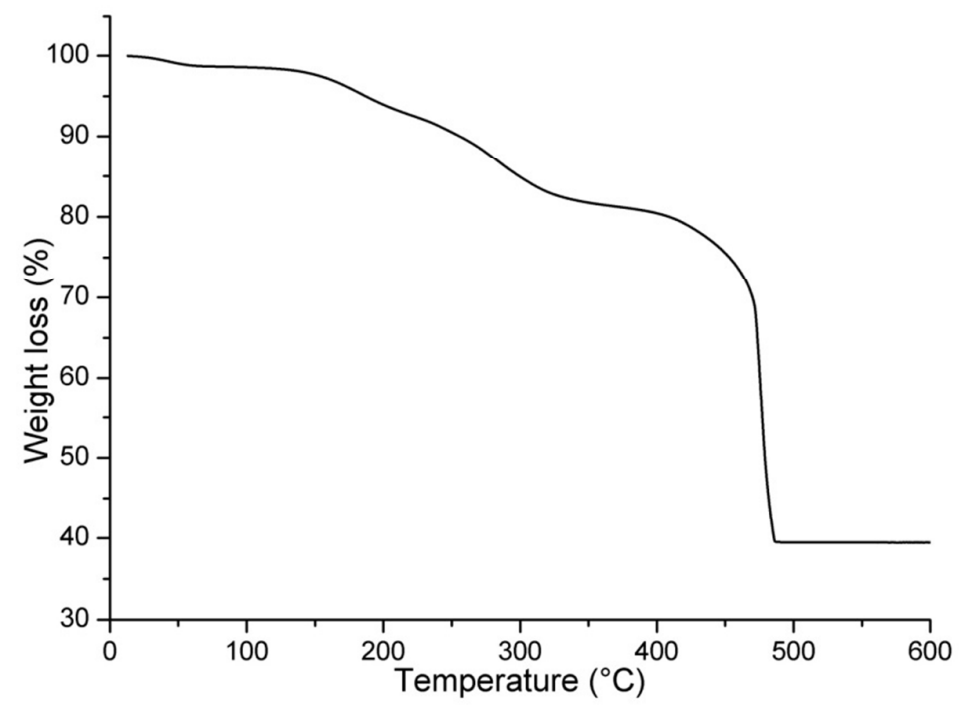

Figure S4d: Thermogravimetric curve of 2 under air atmosphere $\left(5^{\circ} \mathrm{C} \cdot \mathrm{min}^{-1}\right)$.

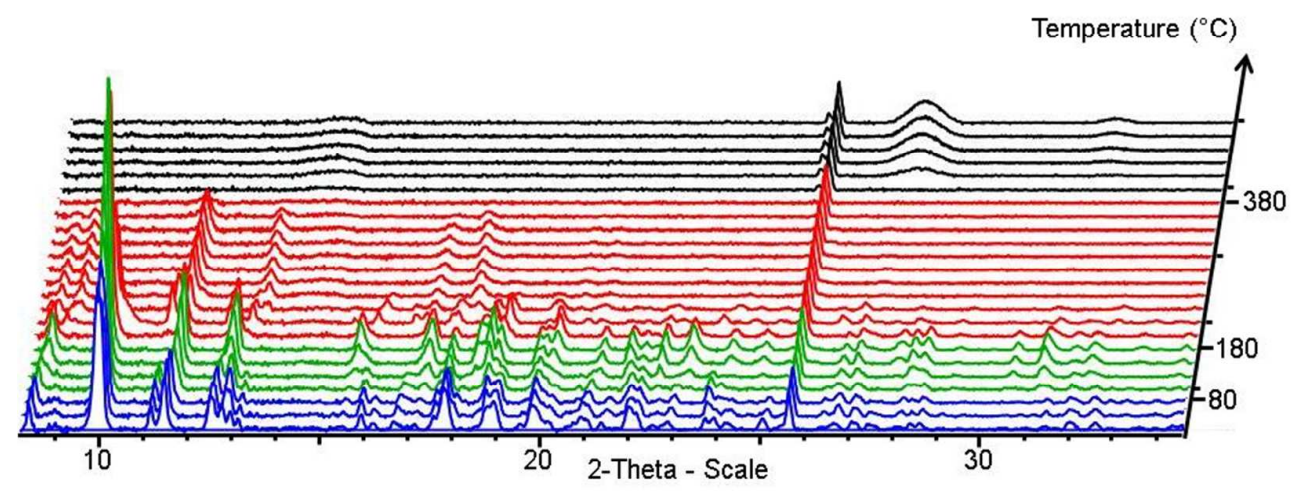

Figure S4e: X-ray thermodiffractogramm of 2 (copper radiation) under air atmosphere. 
Phase 5:
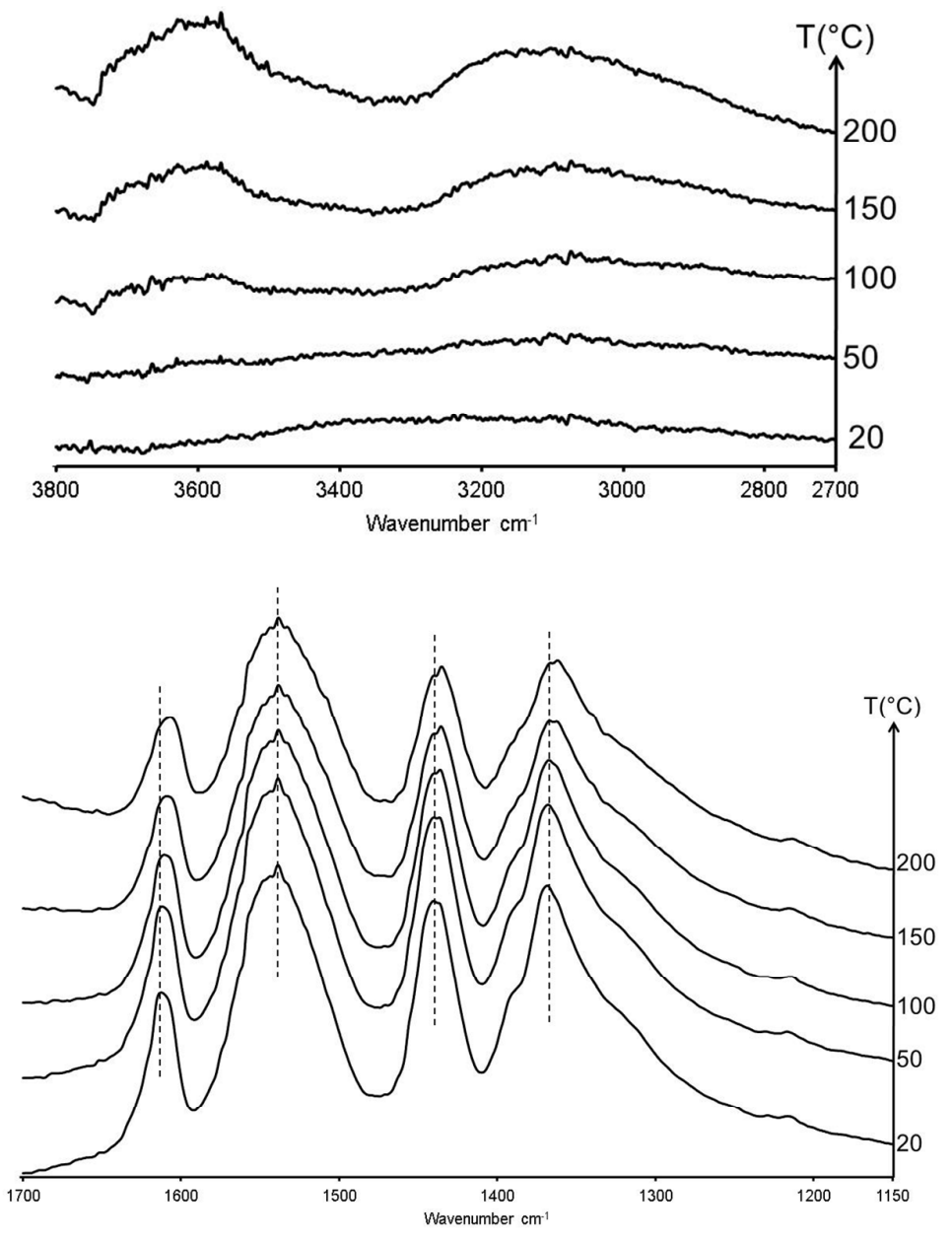

Figure S4f: Evolution of the in situ infrared spectra of 5 as a function of temperature between $\mathrm{RT}$ and $200^{\circ} \mathrm{C}$ in the ranges $3800-2700 \mathrm{~cm}^{-1}$ and $1700-1150 \mathrm{~cm}^{-1}$. 


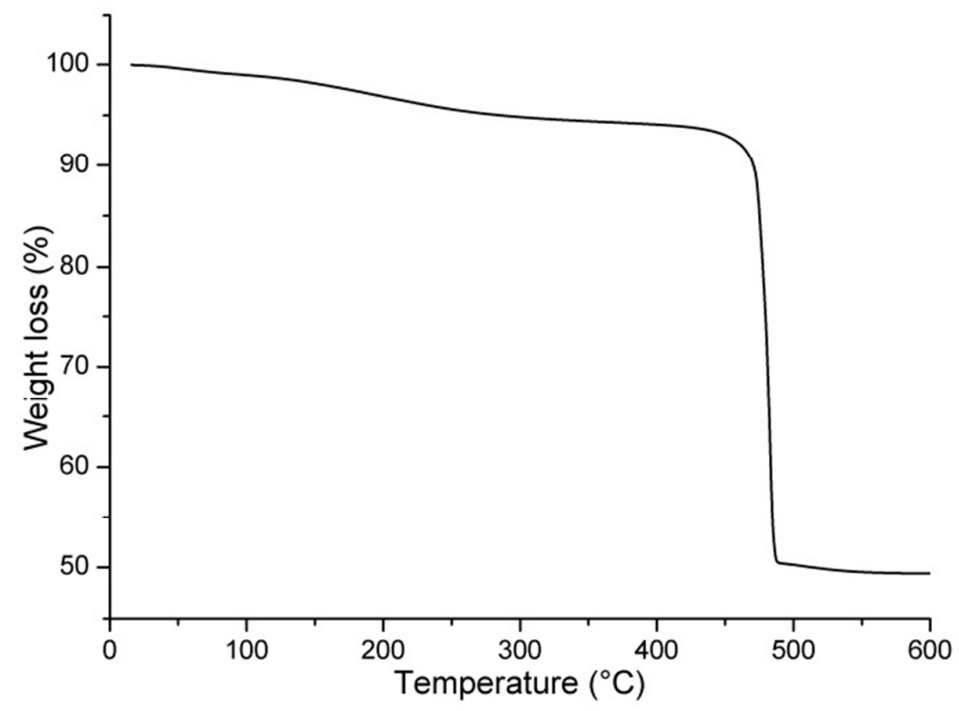

Figure S4g: Thermogravimetric curve of 5 under air atmosphere $\left(5^{\circ} \mathrm{C} \cdot \mathrm{min}^{-1}\right)$.

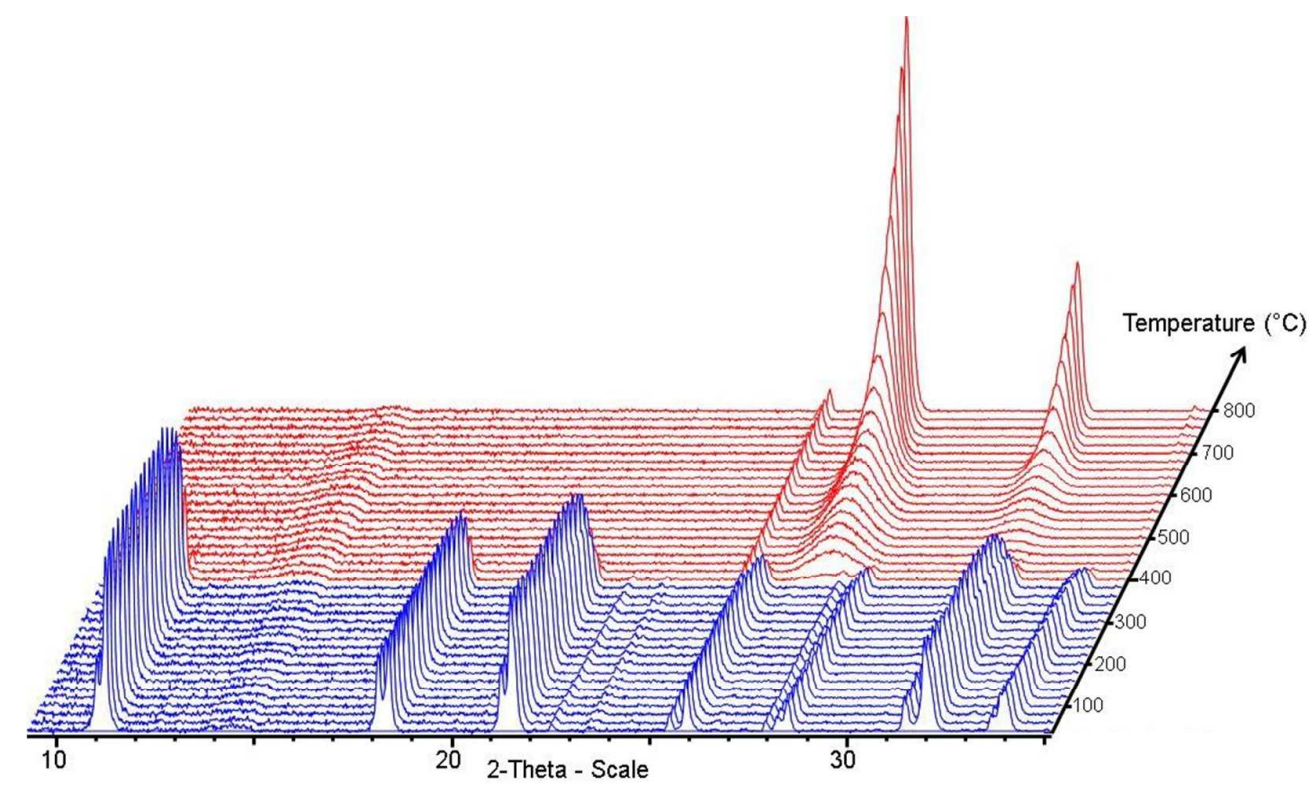

Figure S4h: X-ray thermodiffractogramm of $\mathbf{5}$ (copper radiation) under air atmosphere. 


\section{Gas sorption:}

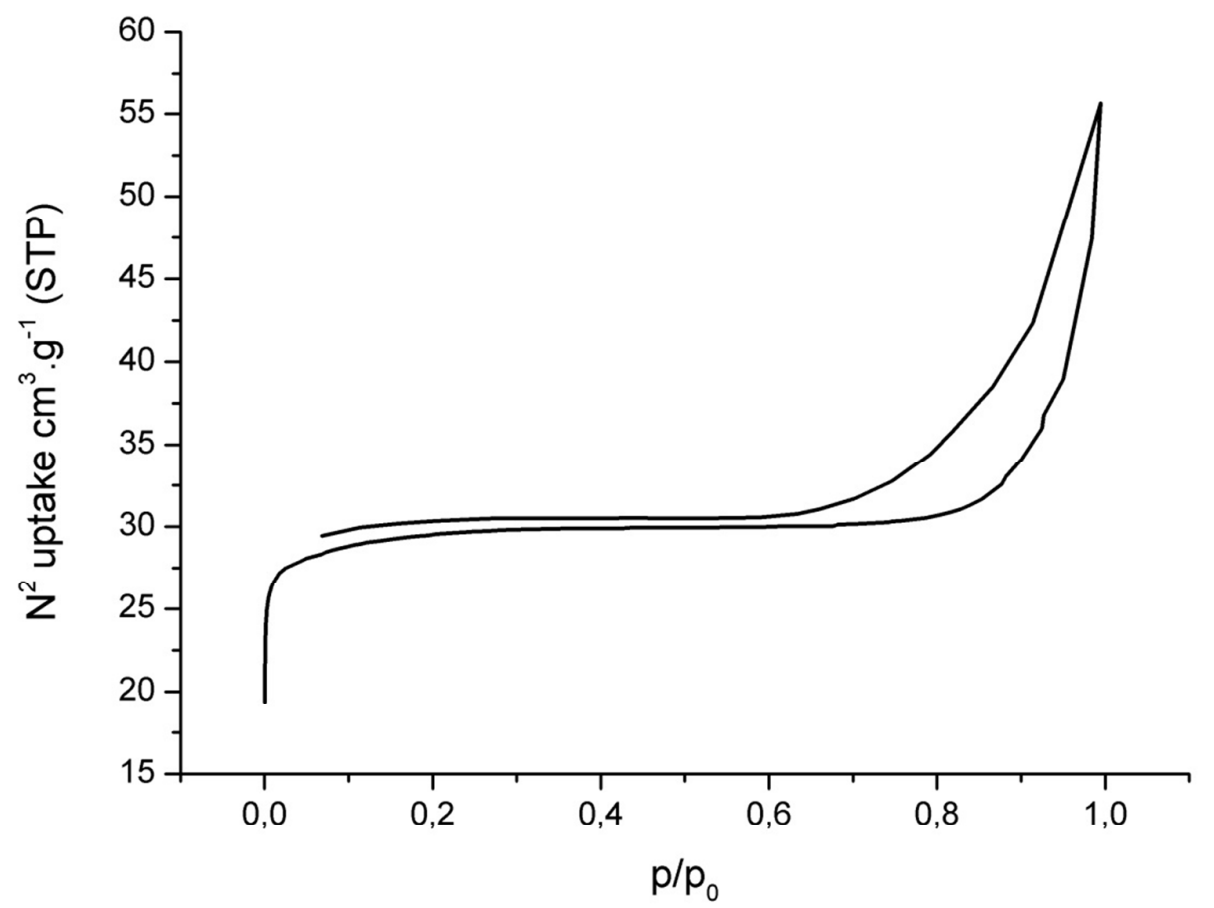

Figure S5a: Nitrogen gas adsorption-desorption isotherm $(77 \mathrm{~K})$ for the activated $1 . \mathrm{p} / \mathrm{p}_{0}$ is the ratio of the gas pressure $(\mathrm{p})$ to saturation pressure $\left(\mathrm{p}_{0}\right)$.

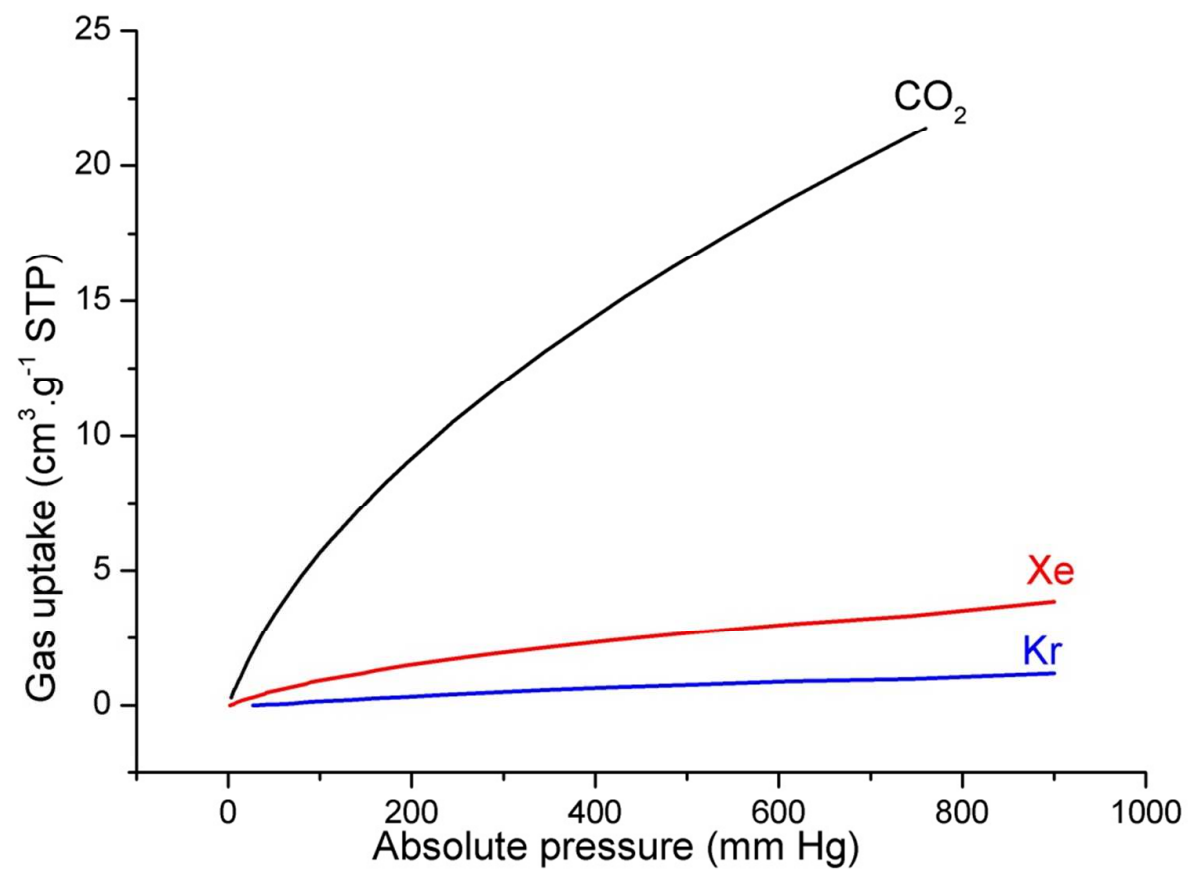

Figure S5b: Carbon dioxide, xenon and krypton adsorption isotherms $(273 \mathrm{~K})$ for the activated 1. 


\section{Elemental analysis: Table S1}

Phase 1

\begin{tabular}{|l|l|l|l|}
\hline & $\mathrm{C} \mathrm{( \% )}$ & $\mathrm{H}(\%)$ & $\mathrm{N}(\%)$ \\
\hline Sample 1 & 25.66 & 2.948 & 2.45 \\
\hline Sample 2 & 25.35 & 2.319 & 2.44 \\
\hline Mean value & 25.51 & 2.933 & 2.44 \\
\hline Deviation, abs. & 0.22 & 0.020 & 0.01 \\
\hline Delta [\%] & 0.32 & 0.029 & 0.01 \\
\hline
\end{tabular}

Phase 2

\begin{tabular}{|l|l|l|l|}
\hline & $\mathrm{C}(\%)$ & $\mathrm{H}(\%)$ & $\mathrm{N}(\%)$ \\
\hline Sample 1 & 28.60 & 3.177 & 2.37 \\
\hline Sample 2 & 28.65 & 3.160 & 2.38 \\
\hline Mean value & 28.62 & 3.169 & 2.38 \\
\hline Deviation, abs. & 0.04 & 0.012 & 0.01 \\
\hline Delta [\%] & 0.05 & 0.017 & 0.01 \\
\hline
\end{tabular}

Phase 5

\begin{tabular}{|l|l|l|l|}
\hline & $\mathrm{C}(\%)$ & $\mathrm{H}(\%)$ & $\mathrm{N}(\%)$ \\
\hline Sample 1 & 22.73 & 1.644 & 1.15 \\
\hline Sample 2 & 22.98 & 1.618 & 1.22 \\
\hline Mean value & 22.86 & 1.631 & 1.18 \\
\hline Deviation, abs. & 0.18 & 0.019 & 0.05 \\
\hline Delta [\%] & 0.25 & 0.027 & 0.07 \\
\hline
\end{tabular}

